\title{
A Case of Painless Aortic Dissection
}

\section{Sisen Zhang ${ }^{1 *}$ and Yingxin Cen ${ }^{2}$}

${ }^{1}$ Department of Emergency, Zhengzhou People's Hospital, Southern Medical University, China

${ }^{2}$ The Second School of Clinical Medicine, Southern Medical University, China

*Corresponding author: Sisen Zhang, Department of Emergency, Zhengzhou People's Hospital, Southern Medical University, China, Tel: 0086-13937-120-886; E-mail: 2362176700@qq.com

Received date: January 29, 2018; Accepted date: January 30, 2018; Published date: February 06, 2018

Citation: Zhang S, Cen Y (2018) A Case of Painless Aortic Dissection. J Intensive Crit Care. Vol.4 No.1:4

\section{Retraction Note:}

The article entitled "A case of painless aortic dissection" has been accepted for publication in the Journal of Intensive \& Critical Care considering the statements provided in the article as personal opinion of the author which was found not having any conflict or biasness towards anything. Publisher took decision to make the article online solely based on the reviewers suggestion which considered the article not but a personal opinion of the author. However, it is found that the author have some personal concerns and issues, therefore, being retracted from the journal.

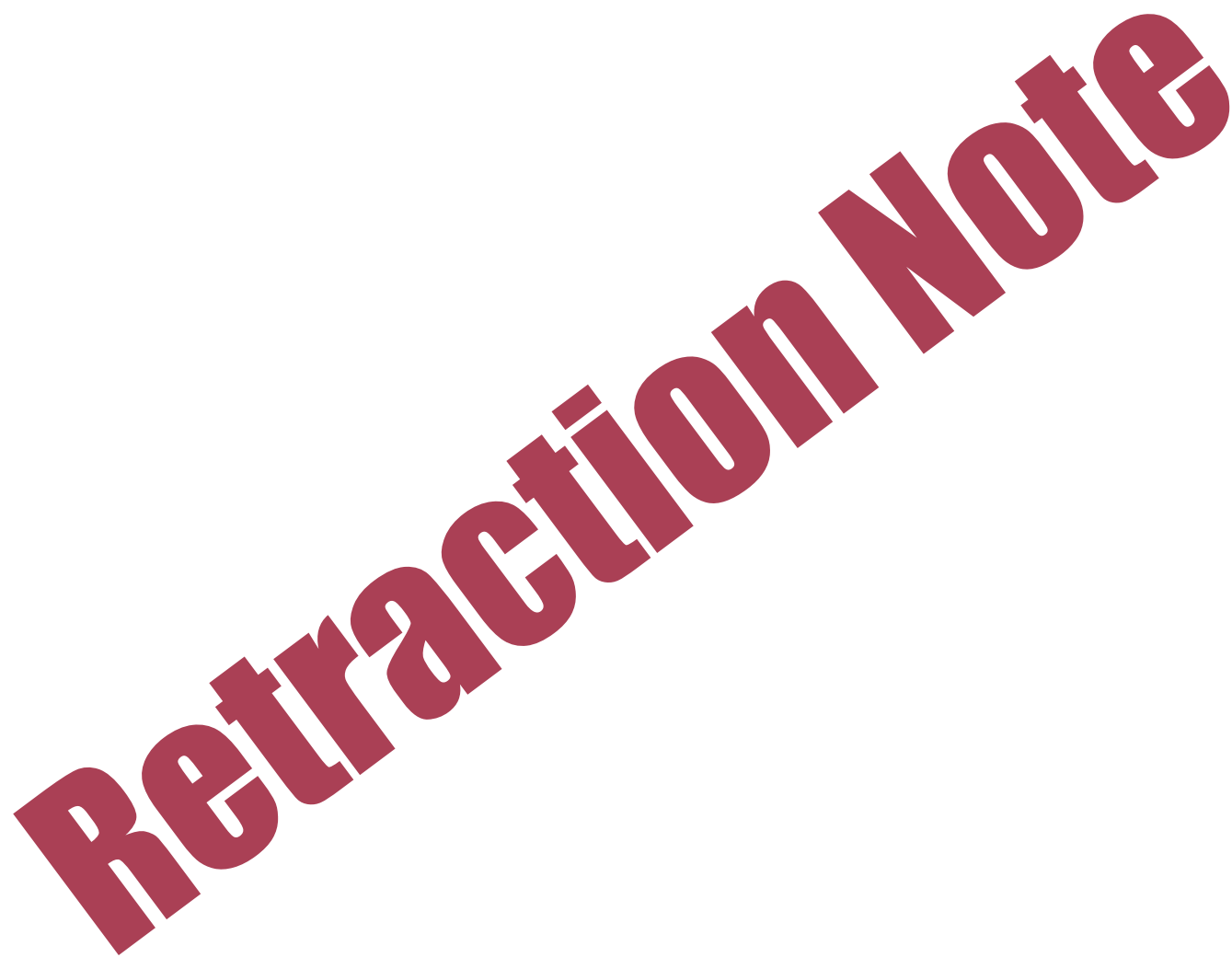

